\title{
Modification of Rule of Mixtures for Tensile Strength Estimation of Circular GFRP Rebars
}

\author{
Young-Jun You ${ }^{1, *}$, Jang-Ho Jay Kim ${ }^{2}$, Ki-Tae Park ${ }^{1}$, Dong-Woo Seo ${ }^{1}$ and Tae-Hee Lee ${ }^{2}$ \\ 1 Structural Engineering Research Institute, Korea Institute of Civil Engineering and Building Technology, \\ 283 Goyangdae-Ro, Ilsanseo-Gu, Goyang-Si 10223, Korea; ktpark@kict.re.kr (K.-T.P.); \\ dwseo@kict.re.kr (D.-W.S.) \\ 2 Concrete Structural Engineering Laboratory, School of Civil and Environmental Engineering, \\ Yonsei University, 50 Yonsei-Ro, Seodaemun-Gu, Seoul 03722, Korea; jjhkim@yonsei.ac.kr (J.-H.J.K.); \\ saintlth@yonsei.ac.kr (T.-H.L.) \\ * Correspondence: yjyou@kict.re.kr; Tel.: +82-31-910-0052
}

Received: 7 November 2017; Accepted: 4 December 2017; Published: 7 December 2017

\begin{abstract}
The rule of mixtures (ROM) method is often used to estimate the tensile strength of fiber reinforced polymers (FRPs) reinforcing bars (rebars). Generally, the ROM method predicts the FRP rebars' modulus of elasticity adequately but overestimates their tensile strength. This may result from defects occurred during manufacture that prevent the used materials from exhibiting a sound performance and the shear-lag phenomenon by transmission of external forces through the surface of the rebar having a circular cross section. Due to the latter, there is a difference in fiber breaking points regarding the fibers located on the surface and fibers located at the center, and thus results in differences between the values calculated from the conventional ROM and the experimental result. In this study, for the purpose of resolving the problem, glass FRP (GFRP) rebars were shaped to have a hollow section at the center of their cross sections and were further subject to tensile strength tests. The test results were further placed under regression analysis and a modified ROM within $\pm 5 \%$ accuracy compared to the experimental value was proposed for GFRP rebars with 13,16 , and 19 mm diameters.
\end{abstract}

Keywords: FRP; rebar; rule of mixtures; tensile strength; hollow section

\section{Introduction}

Fiber reinforced polymers (FRPs) have been mainly utilized in the aeronautical, aerospace, and automotive fields owing to their relatively high strength, lightweight, and non-corroding qualities. The construction sector began paying attention to FRPs in the 1950s as they were recognized as a replacing material capable of solving the problem of degradation of structural performance caused by the corrosion of steel reinforcement in concrete structures. Accordingly, efforts were made to develop FRP reinforcing bars (rebars) in the 1960s and these efforts resulted in the major utilization of FRPs in structures in the 1970s [1]. Internationally, active research on FRP rebars in the U.S., Canada, and Europe led to the commercialization and application of several products in structure construction.

For economic reasons, glass fiber is often used rather than carbon or aramid fiber in the production of FRP rebars [2]. Even if the tensile strength of bars made with glass fiber reinforced polymers (GFRPs) attains strengths of typically around $700 \mathrm{MPa}$ (ISIS 2007), recent achievements have succeeded in developing GFRP rebars with strengths higher than $1000 \mathrm{MPa}[3,4]$.

If the FRP rebars were manufactured perfectly without defects and uniform load applies within the cross section, the materials used to manufacture the FRP rebars are expected to exhibit a sound performance, in which the tested tensile strength values are the same as the value calculated from previous ROM. However, due to production defects that occur as a result of the tangling of fibers 
or appearance of voids, the used materials may not exhibit a sufficiently sound performance [5]. In addition, in general, GFRP rebars intended to replace steel rebars have circular cross-sections with deformed or sand-coated surfaces to properly achieve the transfer of forces to the rebar in concrete. This causes the rebar to experience shear-lag where the fibers located in the periphery of the rebar cross-section receive higher stress than those located at the center. Therefore, unlike the steel rebar, the tensile strength of the FRP rebar is a function of the rebar's diameter [6].

For this reason, the rule of mixtures (ROM) method, which evaluates the tensile strength of FRPs using linear elastic material qualities, tends to overestimate the tensile strength of FRP rebars. It is thus necessary to modify the conventional ROM method to estimate properly the tensile strength of FRP rebars.

Accordingly, this study intends to derive a ROM equation for GFRP rebars assuming that the shear-lag effect causes the stress across the rebar cross-section to be distributed along a quadratic curve when the GFRP rebar is tensioned. To that end, adjustment coefficients within $\pm 5 \%$ accuracy compared to the experimental value are proposed based upon the tensile test results of GFRP rebars with hollow sections and diameters of 13,16 , and $19 \mathrm{~mm}$.

The tensile strength performance of GFRP rebars may differ according to the type of material used (for example, E (electrical)-, S (strength)-, and AR (alkali resistant)-glass) and the method by which they were manufactured. Today, several different types of GFRP rebars have been developed and there exist structural design guidelines regarding the application of some products. However, the development of GFRP rebars is currently a work in progress. In light of this, despite the results of this study not being appropriate for application to all GFRP rebars, the GFRP rebars considered in this research were used to propose a modified ROM that considers only one variable, which was focused on the sound performance of the fiber used in the GFRP rebar (relatively higher tensile strength/fiber content than previously researched GFRP rebars). Due to the linear material feature, this model may help other researchers as an index in the design and evaluation of GRFP rebar through any method like linear interpolation.

\section{Background}

The rule of mixtures (ROM) is a weighted mean used to predict the properties of composite materials such as FRPs including the tensile performance based upon the following assumptions [7]:

(1) One ply is microscopically homogenous, linear elastic, and orthotropic. In addition, it is initially in a stress-free state.

(2) The fiber is homogenous, linear elastic, and well-arranged regularly in space.

(3) The matrix is also homogenous, linear elastic, and isotropic.

(4) There are no voids, and the fiber and the matrix are completely coupled.

Based on these assumptions, the tensile performance of FRP composed of fiber and polymer matrix can be obtained by combining linearly the volume fraction and the tensile properties of the fiber and the matrix as follows [8]:

$$
\begin{aligned}
& \sigma_{F R P}=\sigma_{f} V_{f}+\sigma_{m} V_{m} \\
& E_{F R P}=E_{f} V_{f}+E_{m} V_{m}
\end{aligned}
$$

where $\sigma_{F R P}, \sigma_{f}$, and $\sigma_{m}$, and $E_{F R P}, E_{f}$, and $E_{m}$ indicate the tensile strength (MPa) and the elastic modulus (MPa) of FRP, reinforcing fiber, and matrix, respectively. $V_{m}$ and $V_{f}$ are the volume fractions $(\%)$ of the reinforcing fiber and matrix, respectively.

ROM is the simplest and easiest method to predict the tensile properties of FRP with a given fiber volume fraction and using the characteristics of its components. However, although its prediction of the tensile elastic modulus in the axial direction is effective or accurate, ROM fails to predict accurately the tensile strength [9]. In addition, ROM assumes that the fiber is unidirectionally aligned and stress is uniformly distributed. In reality, the spread of the fiber can be non-homogenous and the 
fiber orientation can be misaligned, resulting in reduced tensile strength of the unidirectional fiber composite [10].

Moreover, ROM also considers that the fiber and the matrix experience identical deformation, as shown in Figure 1. However, since both materials exhibit different tensile behaviors, shear-lag occurs and causes rupture to occur at different points of time.

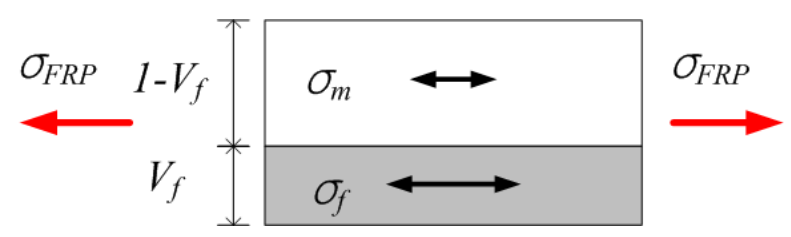

Figure 1. Schematic illustration of deformation of FRP under stress [9].

When a rebar is tensioned by grips, shear-lag will not occur when the bar is made of a highly stiff material such as steel. However, as shown in Figure 2, this is not the case for FRP which combines materials with relatively high stiffness (fiber) and relatively low stiffness (resin). This explains why ROM predicts the elastic modulus of FRP rebars with relatively good accuracy but overestimates the tensile strength.

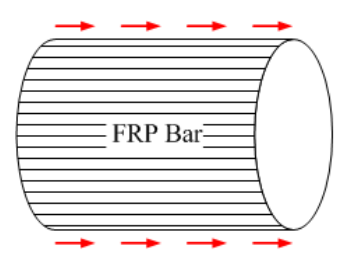

(a)

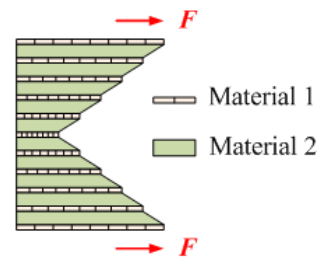

(b)

Figure 2. Shear-lag phenomenon: (a) overview; and (b) longitudinal section.

Accordingly, Lee and Hwang [10] proposed the modified ROM expressed in Equations (3) and (4), in which an effective fiber volume fraction is applied by means of a degradation parameter. The equations are based on the assumption that the ROM-originated strength variation is affected by factors such as the non-homogenous fiber spread in the case of a small fiber volume fraction and the lack of a matrix between some adjacent fibers.

$$
\begin{gathered}
\sigma_{F R P}=\sigma_{f} V_{f e}+\sigma_{m}\left(1-V_{f}\right) \\
V_{f e}=V_{f}(1-P)
\end{gathered}
$$

where $V_{f e}$ is the effective volume fraction of reinforcing fiber (\%) and $P$ is a degradation parameter. Other symbols are same as those in Equations (1) and (2).

Faza and Gangarao [11] developed an analytical model to estimate the tensile strength of FRP rebars based on the mechanics of materials. This model considered the shear-lag effect by assuming that the strain of the bar resulting from the tension introduced by the gripping system is parabolic and axisymmetric in the circular cross-section as shown in Figure 3. The parameter $c$ denoting the thickness of the boundary layer was introduced to relate the curing rates associated with the rebar's size. To establish their model expressed in Equation (5), the authors assumed the strain distribution shown in Figure 3. In this distribution, the strain diminishes parabolically from the outermost part of the rebar to the height of $D / 2-c$, where $D$ is the diameter of the FRP rebar, and shows even distribution afterward to the center with the fiber's extreme strain decreased by $\lambda$.

$$
\sigma_{F R P}=0.5 \sigma_{f}\left[1+2 \lambda-(1-2 c / D)^{2}\right]
$$




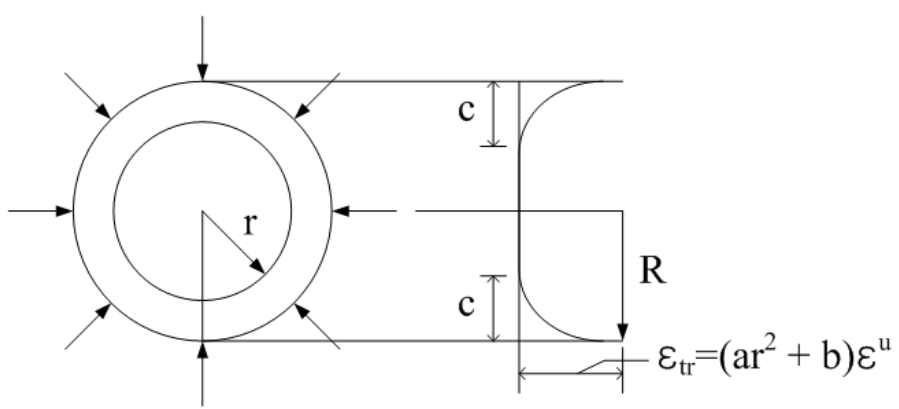

Figure 3. Strain distribution across cross-section of FRP rebar in tension [11].

Equation (5) predicts the actual tensile strength of the FRP rebars quite well when adequate values are used for the parameters. However, the determination of the two parameters $c$ and $\lambda$ depends on the curing rate of the resin and the size of the specimens, respectively.

Despite it being practical to consider performance losses due to incomplete bonds between fibers, voids within the composite, and the non-homogeneous spread of fibers, such elements of incompletion for cases of relatively small bar shaped diameters and long lengths may have very little effect, or an extremely large effort is needed to quantify all such elements of incompletion.

\section{Model for Tensile Strength Estimation}

The tensile strength of the FRP rebars is sensitive not only to the amount and material properties of the fibers but also to various other conditions such as the manufacturing process and fiber arrangement [5]. Moreover, since reinforced fibers are highly vulnerable to lateral loading, the tensile strength of the FRP rebars may differ even according to the grip system used to apply tension as well as to the bond performance between the grip and the FRP rebar surface [12,13].

Considering the difficulty of taking into account all such manufacturing conditions, the following preconditions were assumed macroscopically in this study to develop an equation predicting the tensile strength of FRP rebars.

(1) FRP rebars are made only of a single type of reinforced fiber (especially glass fiber) and resin.

(2) FRP rebars are fabricated through an adequate process, and the so-produced rebars exhibit small variation regarding the tensile strength.

(3) Because the values of material properties of resin are far smaller than those of reinforcing fiber, it is assumed that, for the sake of model simplification, the tensile strength of the FRP rebars is controlled macroscopically only by the quantity of the reinforcing fiber.

(4) There is no transverse shrinkage perpendicular to the longitudinal axis of the rebar.

(5) The grip used to evaluate the tensile strength of the FRP rebars supports the rebars sufficiently up to their breaking load or displays the same performance.

(6) The conventional ROM predicts accurately enough the elastic modulus of FRP rebars.

The equation predicting the tensile strength of the FRP rebars proposed in this research resembles that suggested by Faza and Gangarao [11]. However, considering that the diameter and length of the rebars are sufficiently comparable, the equation is formulated by ignoring the section where the strain is distributed evenly and by assuming that the distribution of stress occurs inside the cross-section as the quadratic curve in Equation (6).

If the distribution of the stress developed in the FRP rebars under tension and close to rupture is axisymmetric and takes the form of a quadratic curve, the stress distribution across the rebar cross-section can be expressed as shown in Figure 4.

$$
f(x)=A x^{2}+B x+C
$$




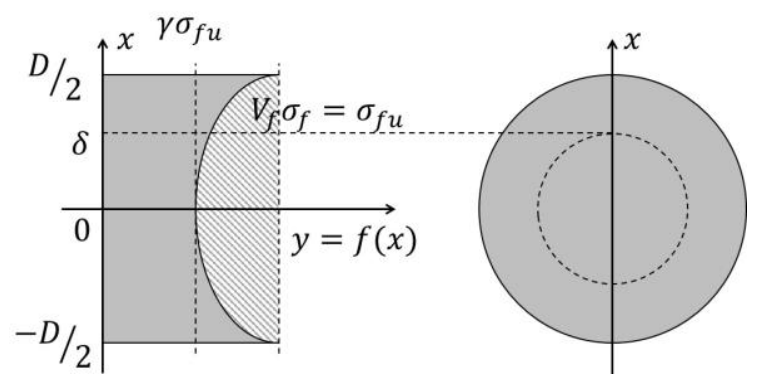

Figure 4. Assumed stress distribution on transversally projected section.

In Figure $4, \sigma_{f u}$ is the ultimate tensile strength of FRP depending on the fiber volume fraction $\left(V_{f}\right) ; \sigma_{f}$ and $D$ are the tensile strength and the diameter of a rebar, respectively; $\delta$ is a radius of any point from the center (which means the radius of hollow section in this paper); and $\gamma$ is a reduction factor of the tensile strength $(0<\gamma<1)$.

The size of the distributed stress can be obtained by subtracting the volume of the paraboloid bowl from the circular cylinder in Figure 5. The volume is computed as the height of the stress multiplied by the area and means thus the force.

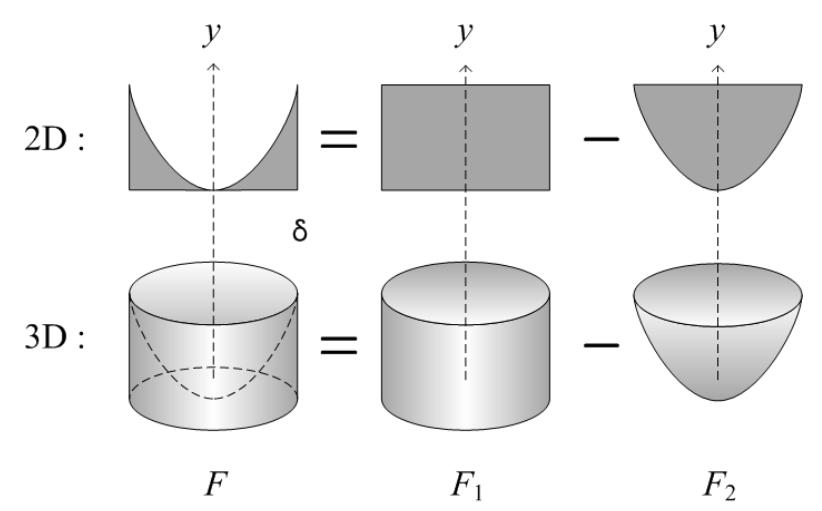

Figure 5. Calculation of peak tensile force.

In this stress distribution, the ultimate tensile strength $\left(\sigma_{f u}\right)$ occurs across the rebar's outer surface while the ultimate tensile strength reduced by $\gamma$ is at work in the center of the cross-section. Therefore, the quadratic curve projected onto the side passes through $\left(0, \gamma \sigma_{f u}\right),\left(D / 2, \sigma_{f u}\right)$, and $\left(-D / 2, \sigma_{f u}\right)$, leading to $C=\gamma \sigma_{f u}, B=0$ and $A=(1-\gamma) \sigma_{f u} /(D / 2)^{2}$.

In Figures 4 and 5 , the volume $F_{1}$ of the cylinder with radius $\delta$ and height $f(\delta)$, and the volume $F_{2}$ of the paraboloid bowl can be obtained as follows:

$$
\begin{gathered}
F_{1}=\pi \delta^{2} f(\delta)=\pi \delta^{2}\left\{\frac{(1-\gamma) \sigma_{f u}}{(D / 2)^{2}} \delta^{2}+\gamma \sigma_{f u}\right\} \\
F_{2}=\pi \int_{\gamma \sigma_{f u}}^{f(\delta)} x^{2} d y=\frac{\pi}{2} \frac{(1-\gamma) \sigma_{f u}}{(D / 2)^{2}} \delta^{4} \\
F=F_{1}-F_{2}
\end{gathered}
$$

Considering the FRP rebar with radius $\delta$ and hollow part in the cross, as shown in Figure 5, the volume $F^{\text {Empty }}$ of the removed part of the composite volume can be obtained by Equation (9), 
and the volume of the full cross-section $F^{\text {Full }}$ can also be obtained by Equation (9) in which $\delta$ in Equations (7) and (8) is replaced by $D / 2$. That is,

$$
\begin{gathered}
F^{\text {Empty }}=F_{1}^{\text {Empty }}-F_{2}^{\text {Empty }}=\frac{\pi}{2} \delta^{2} \sigma_{f u}\left\{\frac{(1-\gamma) \sigma_{f u}}{(D / 2)^{2}} \delta^{2}+2 \gamma\right\} \\
F^{\text {Full }}=\pi\left(\frac{D}{2}\right)^{2} \sigma_{f u}\left(\frac{1+\gamma}{2}\right)=\left(\frac{1+\gamma}{2}\right) A_{F R P} V_{f} \sigma_{f u}
\end{gathered}
$$

where $A_{F R P}$ is the cross-sectional area of the FRP rebar.

Consequently, Equation (11) representing the tensile breaking force of the rebar is a modified ROM because it multiplies Equation (1) by the cross-section area of the rebar and applies the tensile strength reduction rate.

Assuming that, with the exception of the reduced tensile strength, the tensile behavior of the FRP rebar with a hollow section is not different from that of the FRP rebar with a full cross section in terms of the elastic modulus, the tensile strength of the hollow section FRP rebar can be obtained as follows.

$$
F^{\text {Hollow }}=F^{\text {Full }}-F^{\text {Empty }}=\left(\frac{1+\gamma}{2}\right) A_{F R P} V_{f} \sigma_{f u}-\frac{\pi}{2} \delta^{2} \sigma_{f u}\left\{\frac{(1-\gamma) \sigma_{f u}}{(D / 2)^{2}} \delta^{2}+2 \gamma\right\}
$$

The tensile strength of the FRP rebar can be obtained adequately, if the tensile strength change rate $\gamma$ can be obtained from Equation (12) through tension test of the hollow FRP rebar with parts missing in the center of the cross-section.

Unlike the previous ROM model that assumes the external force to be equally distributed across the FRP cross-section, this model features a bar shaped FRP having a circular cross-section that considers actual situations in which external forces are not transmitted to the cross-section but from the side section surface. Due to there being only one variable, it is easier to apply than Equation (5) that uses two variables.

\section{Tensile Test of Hollow GFRP Rebar Specimens}

\subsection{Materials and Manufacturing Process}

The GFRP rebars used in this study are made of E-glass fiber (Owens Corning Korea, Seoul, Korea) and vinyl ester resin (Aekyung Chemical Co., Ltd., Seoul, Korea, Ashland Inc., Covington, KY, UAS). The properties of these materials by manufacturers are listed in Table 1.

Table 1. Material properties of GFRP (glass fiber reinforced polymers) rebar.

\begin{tabular}{cccc}
\hline Material & Designation of Product & Tensile Strength (MPa) & Elastic Modulus (MPa) \\
\hline Resin 1 & HETRON 922 & 86 & 3170 \\
Resin 2 & DION-9100 & 79 & 3216 \\
Core fiber & SE1200 & 2600 & 81,000 \\
\hline
\end{tabular}

The rebars were fabricated by the braidtrusion process of You et al. [5], which is a modified version of the one suggested by Ko et al. [14]. This modified process enhances the overall tensile performance through improved fiber arrangement and reduced voids by applying a definite tension to the fibers used to form reinforced fiber bundles and ribs.

\subsection{Hollow GFRP Rebar Specimens}

Sets of GRFP rebars with two different diameters and four different hollowness ratios were fabricated to investigate the changes in the tensile properties according to the hollowness ratio of the GFRP rebars. Plain GFRP rebars (in other words, rebars with solid cross-section) were also 
considered to provide reference specimens for the comparison of the tensile properties with respect to the hollowness ratio. The hollow GFRP rebars were manufactured by inserting tubes with different diameters inside the rebars. Table 2 lists the considered specimens with their designation, specifications, and quantities.

Table 2. Test specimens.

\begin{tabular}{ccccc}
\hline Specimen & Quantity & Diameter $(\mathbf{m m})$ & Ratio of Hollow Section & Number of Roving \\
\hline D16HD0 & 5 & 15.9 & - & 158 \\
D16HD6 & 6 & 16.0 & $14.1 \%$ & 129 \\
D16HD8 & 6 & 16.0 & $25.0 \%$ & 112 \\
D16HD10 & 6 & 16.0 & $39.1 \%$ & 91 \\
D16HD12 & 6 & 16.0 & $56.3 \%$ & 65 \\
D19HD0 & 3 & 18.6 & - & 217 \\
D19HD6 & 6 & 18.6 & $10.4 \%$ & 196 \\
D19HD8 & 6 & 18.7 & $18.3 \%$ & 180 \\
D19HD10 & 6 & 18.8 & $28.4 \%$ & 159 \\
D19HD12 & 6 & 19.0 & $39.7 \%$ & 133 \\
\hline
\end{tabular}

In the specimen designation of Table 2, $\mathrm{D}$ followed by a two-digit number denotes the outer diameter of the GFRP rebar, and HD indicates the diameter of the hollow tube inserted inside the GFRP rebar. For instance, D19HD8 designates the specimen with a 19-mm diameter for the whole GFRP rebar cross-section in which a hollow tube with an external diameter of $8 \mathrm{~mm}$ is inserted. The diameter of the reinforcing bars in Table 2 is measured at parts without ribs.

Polyurethane tubes were used to form the hollow section within the GFRP rebar cross section. As shown in Figure 6, a fixture was used to control the centrality of the tube inside the glass fiber bundles. Figure 7 shows the cross-sections of the so-fabricated hollow GFRP rebars.

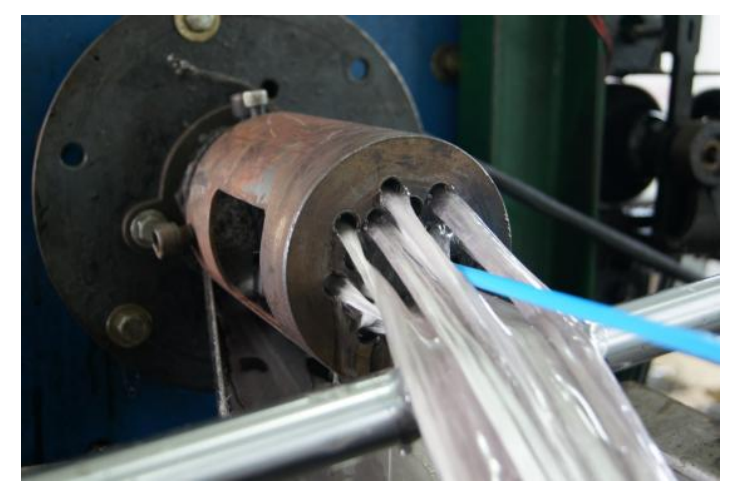

Figure 6. Tube insertion for hollow section.

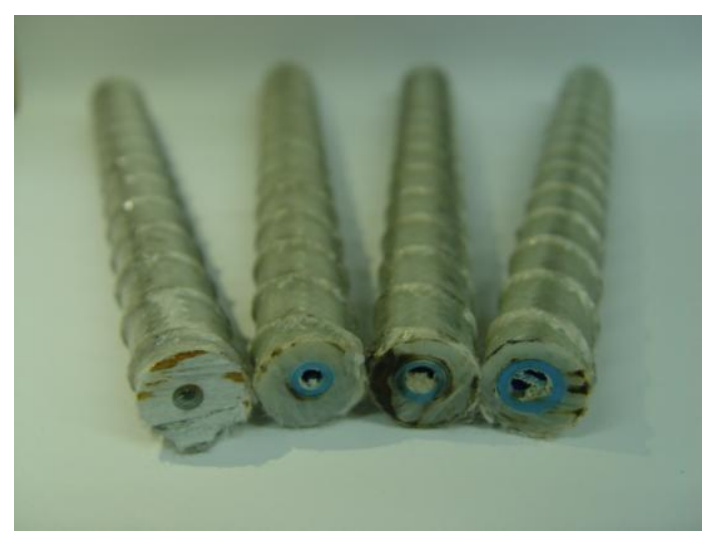

Figure 7. Cross-section of hollow GFRP rebars (D16). 
The finished GFRP rebars were cut to a definite length, and cylindrical steel pipes were positioned at the ends to form the grip in compliance with CSA [15]. These steel pipes have respective thickness and length of $5.1 \mathrm{~mm}$ and $700 \mathrm{~mm}$ for the D16 rebars, and $7.1 \mathrm{~mm}$ and $1000 \mathrm{~mm}$ for the D19 rebars. The caps placed on both ends of the steel pipes are hollowed at their center to allow the rebar be inserted centrally in the steel pipes. The grips were first made on one side of the rebar and the space between the steel pipe and the rebar was filled with non-shrinkage mortar. The rebars were placed straight by means of holders and curing was conducted for seven days. Figure 8 shows a sample of GFRP rebar specimens prepared for tensile test.

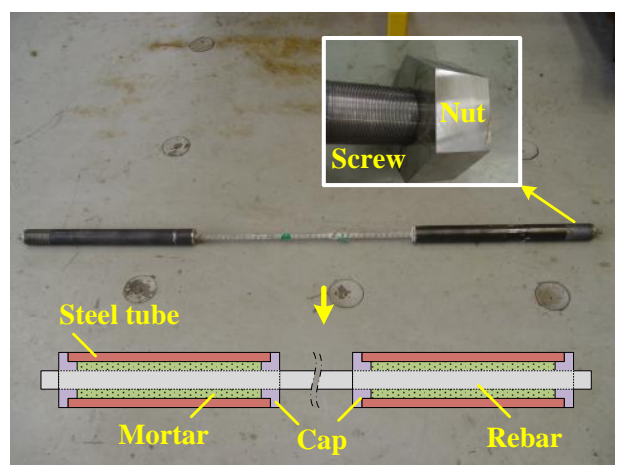

Figure 8. Preparation of specimens for tensile test.

\subsection{Test Set-Up}

As shown in Figures 8 and 9, one end of the cylindrical steel pipe forming the grip was threaded to fasten a nut to hold the specimen and apply tension on the two ends of the grip.

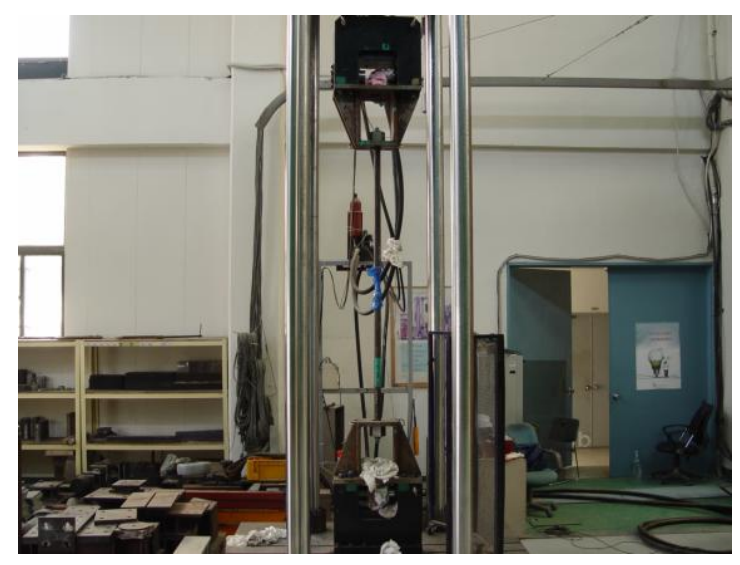

Figure 9. Tensile test set-up.

The so-prepared specimen was then installed in a universal testing machine (UTM) with capacity of $1000 \mathrm{kN}$ and an electrical resistance strain gauge was attached to the middle of the rebar's length to measure the strain during test. The place where the strain gauge was attached was cleaned softly, not grinded because the loss of cross-section would affect the tensile capacity. Tensile test was performed through displacement control and a data logger (TDS530 produced in Tokyo Sokki Kenkyujo Co., Ltd., Tokyo, Japan) was used to record the load and corresponding strain.

\section{Results}

\subsection{Tensile Behavior of GFRP Rebar}

Figure 10 plots the tensile stress-strain curves in which the stress is the UTM's load divided by the area of specimen and the strain is the one measured at the middle of the rebar's length. The curves 
indicate a linear relationship between the tensile strength and the strain curves, and the occurrence of sudden rupture at the peak load. This is the typical material behavior of FRP where the linear increase is followed by brittle failure. The maximum tensile strength and the elastic modulus change with respect to the hollowness ratio, and tend to decrease with a larger hollowness ratio. Table 3 lists the maximum tensile strength and elastic modulus of the considered specimens. The maximum tensile strengths were calculated from dividing measured maximum loads by solid cross-section areas without considering the hollowness because the value calculated from net cross-section area with considering the hollowness means the tensile strength of a bar with smaller diameter and solid section (for example, the net area of a bar with $16 \mathrm{~mm}$ and $9.7 \mathrm{~mm}$ of outer and hollow diameters, respectively, is same with the solid area of a bar with $12.7 \mathrm{~mm}$ diameter). The measured average diameters of the specimens were all $16.0 \mathrm{~mm}$, except for D16HD0 $(15.9 \mathrm{~mm})$. It appears that, apart from specimens D16HD8 and D16HD12, the coefficient of variation (C.O.V) obtained by dividing the standard deviation (S.DEV) by the mean remains below $6.4 \%$ and indicates consistency among the experimental values.

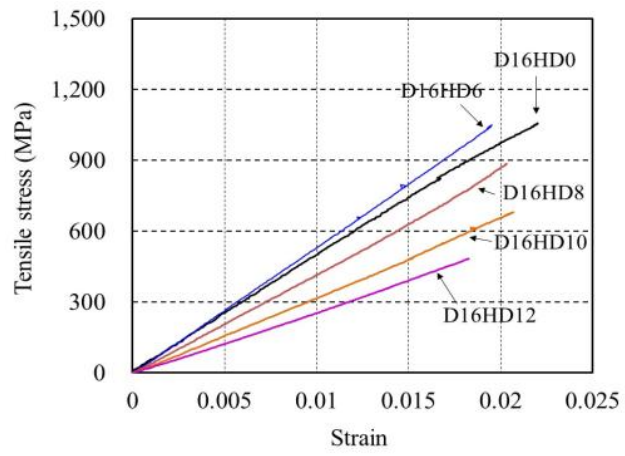

(a)

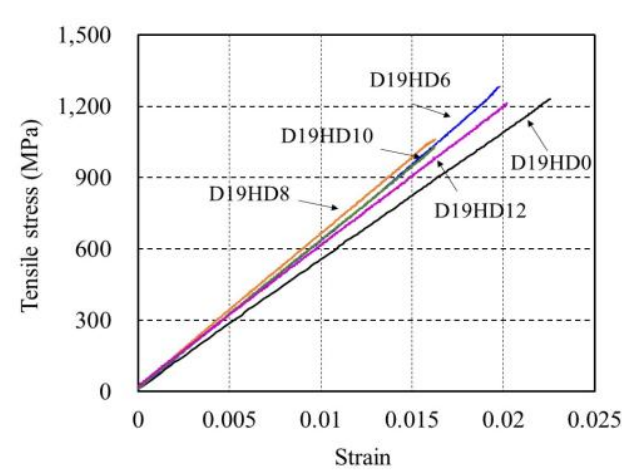

(b)

Figure 10. Tensile behavior of specimens: (a) D16; and (b) D19.

Table 3. Tensile test results of plain and hollow GFRP rebar specimens.

\begin{tabular}{cccccccc}
\hline $\begin{array}{c}\text { Specimen } \\
\text { and } \\
\text { Values }\end{array}$ & $\begin{array}{c}\text { Peak } \\
\text { Load (N) }\end{array}$ & $\begin{array}{c}\text { Tensile } \\
\text { Strength } \\
\mathbf{( M P a )}\end{array}$ & $\begin{array}{c}\text { Elastic } \\
\text { Modulus } \\
\mathbf{( M P a )}\end{array}$ & $\begin{array}{c}\text { Specimen } \\
\text { and Values }\end{array}$ & $\begin{array}{c}\text { Peak } \\
\text { Load (N) }\end{array}$ & $\begin{array}{c}\text { Tensile } \\
\text { Strength } \\
\mathbf{( M P a )}\end{array}$ & $\begin{array}{c}\text { Elastic } \\
\text { Modulus } \\
\text { (MPa) }\end{array}$ \\
\hline D16HD0 & 213,191 & 1074 & 49,402 & D19HD0 & 330,210 & 1218 & 53,520 \\
& 209,767 & 1056 & 46,798 & & 333,300 & 1229 & 55,180 \\
mean & 213,848 & 1077 & 50,681 & & 306,760 & 1131 & 56,519 \\
S.DEV. & 212,269 & 1069 & 48,960 & mean & 323,423 & 1193 & 55,073 \\
C.O.V & 2191 & 11 & 1979 & S.DEV. & 14,513 & 54 & 1502 \\
\hline D16HD6 & $1.0 \%$ & $1.0 \%$ & $4.0 \%$ & C.O.V & $4.5 \%$ & $4.5 \%$ & $2.7 \%$ \\
& 217,120 & 1080 & 46,916 & D19HD6 & 312,530 & 1147 & 55,623 \\
& 211,250 & 1051 & 53,008 & & 301,480 & 1106 & 56,681 \\
& 203,650 & 1013 & 46,237 & & 308,260 & 1131 & 57,229 \\
& 221,400 & 1101 & 51,907 & & 280,370 & 1029 & 55,190 \\
mean & 207,710 & 1033 & 47,131 & & 304,420 & 1117 & 57,505 \\
S.DEV. & 202,160 & 1005 & - & & 277,080 & 1016 & 59,276 \\
C.O.V & 210,548 & 1047 & 49,040 & mean & 297,357 & 1091 & 56,917 \\
\hline D16HD8 & 7582 & 38 & 3161 & S.DEV. & 14,938 & 55 & 1464 \\
& $176 \%$ & $3.6 \%$ & $6.4 \%$ & C.O.V & $5.0 \%$ & $5.0 \%$ & $2.6 \%$ \\
\hline 178,360 & 879 & 42,314 & D19HD8 & 236,600 & 863 & 52,641 \\
& 176,520 & 876 & 41,436 & & 246,140 & 898 & 49,577 \\
& 179,780 & 894 & 40,710 & & 248,740 & 908 & 50,267 \\
& & & & & 230,930 & 843 & 54,674 \\
\hline
\end{tabular}


Table 3. Cont.

\begin{tabular}{|c|c|c|c|c|c|c|c|}
\hline $\begin{array}{c}\text { Specimen } \\
\text { and } \\
\text { Values }\end{array}$ & $\begin{array}{c}\text { Peak } \\
\text { Load (N) }\end{array}$ & $\begin{array}{c}\text { Tensile } \\
\text { Strength } \\
\text { (MPa) }\end{array}$ & $\begin{array}{c}\text { Elastic } \\
\text { Modulus } \\
\text { (MPa) }\end{array}$ & $\begin{array}{l}\text { Specimen } \\
\text { and Values }\end{array}$ & $\begin{array}{c}\text { Peak } \\
\text { Load }(\mathrm{N})\end{array}$ & $\begin{array}{c}\text { Tensile } \\
\text { Strength } \\
\text { (MPa) }\end{array}$ & $\begin{array}{c}\text { Elastic } \\
\text { Modulus } \\
\text { (MPa) }\end{array}$ \\
\hline & 181,870 & 905 & 41,146 & & 239,260 & 873 & 50,036 \\
\hline & 172,470 & 858 & - & & - & - & - \\
\hline mean & 177,638 & 884 & 42,922 & mean & 240,334 & 877 & 51,439 \\
\hline S.DEV. & 3213 & 16 & 3449 & S.DEV. & 7209 & 26 & 2163 \\
\hline C.O.V & $1.8 \%$ & $1.8 \%$ & $8.0 \%$ & C.O.V & $3.0 \%$ & $3.0 \%$ & $4.2 \%$ \\
\hline \multirow[t]{6}{*}{ D16HD10 } & 131,050 & 652 & 35,680 & D19HD10 & 205,860 & 746 & 49,664 \\
\hline & 133,670 & 665 & 33,663 & & 199,220 & 722 & 46,453 \\
\hline & 146,530 & 729 & 34,246 & & 203,320 & 736 & 44,988 \\
\hline & 137,170 & 682 & 31,801 & & 203,690 & 738 & 45,080 \\
\hline & 133,060 & 662 & 34,370 & & - & - & - \\
\hline & 129,790 & 646 & 37,302 & & - & - & - \\
\hline mean & 135,212 & 672 & 34,510 & mean & 203,023 & 735 & 46,546 \\
\hline S.DEV. & 6094 & 30 & 1861 & S.DEV. & 2772 & 10 & 2184 \\
\hline C.O.V & $4.5 \%$ & $4.5 \%$ & $5.4 \%$ & C.O.V & $1.4 \%$ & $1.4 \%$ & $4.7 \%$ \\
\hline \multirow[t]{6}{*}{ D16HD12 } & 86,330 & 429 & 28,130 & D19HD12 & 194,500 & 684 & 38,819 \\
\hline & 89,500 & 445 & 29,762 & & 207,820 & 731 & 35,442 \\
\hline & 97,260 & 484 & 26,079 & & 182,040 & 640 & 34,792 \\
\hline & 92,350 & 459 & 26,601 & & 207,730 & 730 & 33,410 \\
\hline & 83,030 & 413 & 22,041 & & 189,390 & 666 & 37,175 \\
\hline & 90,580 & 451 & 25,959 & & 189,740 & 667 & 32,999 \\
\hline mean & 89,842 & 447 & 26,429 & mean & 195,203 & 686 & 35,439 \\
\hline S.DEV. & 4914 & 24 & 2593 & S.DEV. & 10,521 & 37 & 2233 \\
\hline C.O.V & $5.5 \%$ & $5.5 \%$ & $9.8 \%$ & C.O.V & $5.4 \%$ & $5.4 \%$ & $6.3 \%$ \\
\hline
\end{tabular}

S.DEV: standard deviation; C.O.V: coefficient of variation.

\subsection{Regression Analysis}

Regression analysis can be performed easily by the least squares method because the assumed tensile stress distribution curve expressed in Equation (6) includes one independent variable and one dependent variable. The resulting regression equation must be verified for each specimen to determine its agreement with the measured values. This can be done using the coefficient of determination $R^{2}$ of which value runs between 0 and 1 , with $R^{2}=1$ indicating that the sample regression line fits perfectly with the data.

The reduction factor $\gamma$ of the tensile strength can be obtained by regression analysis of the values in Table 3 and Equations (1) and (6)-(12). The results are $\gamma=0.31843$ for D16 specimens and $\gamma=0.29549$ for D19 specimens. Applying these values in Equation (11) leads to the following estimation of the tensile strength in Equation (13) for D16 specimens and Equation (14) for D19 specimens.

$$
\begin{aligned}
& F_{\mathrm{D} 16}^{\text {Full }}=0.659 A_{F R P} V_{f} \sigma_{f} \\
& F_{\mathrm{D} 19}^{\text {Full }}=0.648 A_{F R P} V_{f} \sigma_{f}
\end{aligned}
$$

As explained above, the tensile strength of the FRP rebars is a function of the rebar diameter and tends to decrease with a larger diameter. Figure 11 indicates the change in the tensile strength according to the diameter for the commercial product Aslan100 [16]. It appears that the tensile strength of the reinforcing bar reduces quasi-linearly with the increase of the diameter.

Accordingly, assuming a linear relationship between the tensile strength and the diameter of the GFRP reinforcing bar, the tensile strength can be estimated by Equation (15) for the $13 \mathrm{~mm}$-diameter rebar through linear interpolation of Equations (13) and (14).

$$
F_{\mathrm{D} 13}^{\text {Full }}=0.674 A_{F R P} V_{f} \sigma_{f}
$$




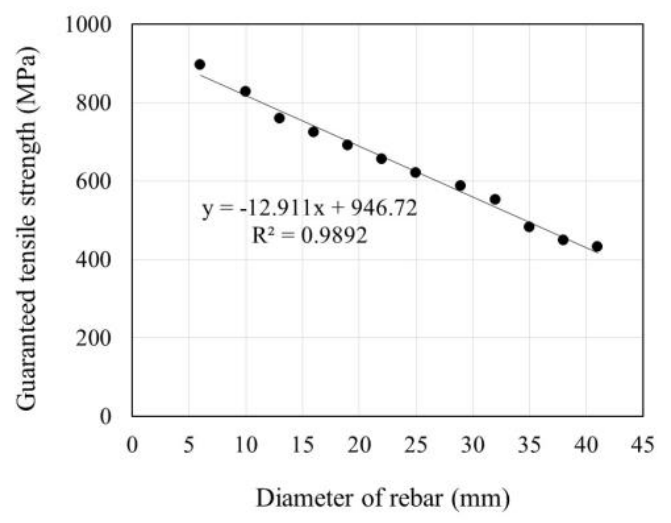

Figure 11. Change in tensile strength of GFRP rebar according to diameter [16].

\subsection{Verification of Estimation Model}

Although the actual fiber content is unknown because burn-out test was not performed on the specimens considered in this research, many researchers reported that the ROM provides adequate predictions of the elastic modulus of FRP materials. Thus, if the influence of the resin is ignored, as in this study, the fiber content listed in Table 4 can be estimated by Equation (2) and by ignoring the contribution of the matrix to the tensile strength.

Table 4. Calculation of fiber volume fraction.

\begin{tabular}{ccccc}
\hline \multirow{2}{*}{ Rebar } & \multirow{2}{*}{$\begin{array}{c}\text { Measured Inner } \\
\text { Diameter }(\mathbf{m m})\end{array}$} & \multicolumn{2}{c}{ Elastic Modulus (GPa) } & Calculated Volume Fraction \\
\cline { 3 - 4 } & & Glass Fiber ${ }^{\mathbf{a}}$ & Rebar $^{\mathbf{b}}$ & \\
\hline D13 [5] & 12.7 & 73 & 49 & $67.6 \%$ \\
D13 [17] & 12.7 & 81 & 52 & $63.8 \%$ \\
D13 [18] & 12.5 & - & 47 & $55.0 \%$ \\
D16 & 16.0 & 81 & 49 & $60.4 \%$ \\
D19 [19] & 18.6 & 73 & 47 & $64.0 \%$ \\
D19 & 18.6 & 81 & 55 & $68.0 \%$ \\
\hline
\end{tabular}

Table 5 compares the tensile strengths predicted by the conventional and modified ROMs to validate the developed estimation model using the experimental results of this study and those of previous tensile strength tests carried out by other researchers. It appears that the modified ROM provides accuracy within $\pm 5 \%$, whereas the conventional $\mathrm{ROM}$ overestimates the tensile strength of the GFRP reinforcing bars by more than $40 \%$.

Table 5. Comparison of tensile strengths predicted by conventional ROM and modified ROM using Equations (13)-(15).

\begin{tabular}{|c|c|c|c|c|c|c|c|}
\hline \multirow{2}{*}{ Rebar } & \multicolumn{2}{|c|}{$\begin{array}{c}\text { Tensile Strength } \\
\text { (MPa) }\end{array}$} & \multirow{2}{*}{$\begin{array}{l}\text { Modification } \\
\text { Factor }\end{array}$} & \multicolumn{4}{|c|}{ Predicted Tensile Strength (MPa) } \\
\hline & $\begin{array}{l}\text { Glass } \\
\text { Fiber }^{a}\end{array}$ & Rebar $^{b}$ & & ROM * & ROM/Experiment & $\begin{array}{l}\text { Modified } \\
\text { ROM }\end{array}$ & $\begin{array}{c}\text { Modified } \\
\text { ROM/Experiment }\end{array}$ \\
\hline D13 [5] & 2580 & 1132 & 0.674 & 1745 & $154 \%$ & 1174 & $104 \%$ \\
\hline D13 [17] & 2600 & 1103 & 0.674 & 1660 & $150 \%$ & 1117 & $101 \%$ \\
\hline D13 [18] & 2600 & 975 & 0.674 & 1430 & $147 \%$ & 965 & $99 \%$ \\
\hline D16 & 2600 & 1069 & 0.659 & 1572 & $147 \%$ & 1036 & $97 \%$ \\
\hline D19 [19] & 2580 & 1030 & 0.648 & 1651 & $160 \%$ & 1069 & $104 \%$ \\
\hline D19 & 2600 & 1193 & 0.648 & 1768 & $148 \%$ & 1145 & $96 \%$ \\
\hline
\end{tabular}

${ }^{*}$ From Equations (1) and (2). 


\section{Conclusions}

Considering that the conventional ROM overestimates the tensile strength of FRP rebars with circular cross-section, this study proposed modified ROM coefficients based upon the tensile strength test results obtained for a series of GFRP rebars with various diameters and hollowness ratios. According to the type and volume of the materials used, FRP bars each present a different performance, thus it is not appropriate to extrapolate from this model and apply the results generally. However, the results of this study are expected to be applicable for use as an index for design and evaluation purposes by researchers developing GFRP rebars. The conclusions found through this research are as follows.

(1) For a specific composite that is bar shaped and has a circular cross-section, a more realistic phenomenon is realized, whereby the tensile force is transferred not through the cross-section but the side surface of the bar and this resulting uniform stress distribution is included in the proposed ROM.

(2) The proposed ROM has just one parameter to explain the shear-lag effect of the FRP bar under tension and the parameter was determined from tensile test results for GFRP rebars with a hollow section since the fiber content is the main factor for the tensile performance of a FRP outlined in the conventional ROM.

(3) The proposed ROM provides accuracy within $\pm 5 \%$, whereas the conventional ROM overestimates the tensile strength of the GFRP reinforcing bars with diameters of 13, 16, and $19 \mathrm{~mm}$ by more than $40 \%$.

Acknowledgments: This project was supported by KICT's (Korea Institute of Civil Engineering and Building Technology) basic project named "Harbor Structure's Performance Improvement Technologies Using FRP Composites".

Author Contributions: Young-Jun You and Dong-Woo Seo designed the experiments; Ki-Tae Park guided the entire work; Jang-Ho Jay Kim and Tae-Hee Lee analyzed the data and corrected the manuscript; and Young-Jun You wrote the manuscript.

Conflicts of Interest: The authors declare no conflict of interest.

\section{References}

1. ISIS Canada. Design Manual 3: Reinforcing Concrete Structures with Fiber Reinforced Polymers; The Canadian Network of Centers of Excellence on Intelligent Sensing for Innovative Structures: University of Manitoba, Winnipeg, MB, Canada, 2007.

2. Benmokrane, B.; El-Salakawy, E.; El-Ragaby, A.; Lackey, T. Designing and Testing of Concrete Bridge Decks Reinforced with Glass FRP Bars. J. Bridge Eng. 2006, 11, 217-229. [CrossRef]

3. VORD. 2014. Available online: http:// www.vrod.ca/en/downloads.asp (accessed on 24 April 2014).

4. BPComposite. 2014. Available online: http://www.bpcomposites.com/downloads (accessed on 24 April 2014).

5. You, Y.; Kim, J.; Kim, S.; Park, Y. Methods to enhance the guaranteed tensile strength of GFRP rebar to $900 \mathrm{MPa}$ with general fiber volume fraction. Constr. Build. Mater. 2015, 75, 54-62. [CrossRef]

6. Cusson, R.; Xi, Y. The Behavior of Fiber-Reinforced Polymer Reinforcement in Low Temperature Environmental Climates; Report No. CDOT-DTD-R-2003-4; Department of Civil, Environmental \& Architectural Engineering, University of Colorado: Boulder, CO, USA, 2002.

7. Lee, D.G.; Jeong, M.Y.; Choi, J.H.; Cheon, S.S.; Chang, S.H.; Oh, J.H. Composite Materials; Hongrung Publishing Company: Seoul, Korea, 2007; pp. 173-176. (In Korean)

8. Campbell, F.C. Structural Composite Materials; ASM International: Materials Park, OH, USA, 2010; ISBN 978-1-61503-037-8.

9. Hull, D.; Clyne, T.W. An Introduction to Composite Materials, 2nd ed.; Cambridge University Press: Cambridge, UK, 2006; pp. 66-67.

10. Lee, C.; Hwang, W. Modified rule of mixtures for prediction of tensile strength of unidirectional fiber-reinforced composites. J. Mater. Sci. Lett. 1998, 17, 1601-1603. [CrossRef] 
11. Faza, S.; GangaRao, H. Glass FRP reinforcing bars for concrete. In Fibre-Reinforced Plastic (FRP) Reinforcement for Concrete Structures: Properties and Applications; Nanni, A., Ed.; Elsevier: Amsterdam, The Netherland, 1993; pp. 167-188.

12. Protasio, F.C.; Nicholas, J.C. Tensile and nondestructive testing of FRP bars. J. Compos. Constr. 1998, 2, $17-27$.

13. Shicheng, T. Bond of Glass-Fiber-Reinforced-Plastic Reinforcing Bars to Concrete. Ph.D. Thesis, the University of Arizona, Tucson, AZ, USA, 1994; p. 53.

14. Ko, F.K.; Somboonsong, W.; Harris, H.G. Fiber architecture based design of ductile composite rebars for concrete structures. In Proceedings of the 11th International Conference Composite Materials; Scott, M.L., Ed.; Woodhead Publishing: Cambridge, UK, 1997; p. 4.

15. Canadian Standards Association S806-02. Design and Construction of Building Components with Fiber Reinforced Polymers; CSA: Toronto, ON, Canada, 2002.

16. ASLAN. 2014. Available online: http://aslanfrp.com/aslan100/Resources/Aslan100a.pdf (accessed on 24 April 2014).

17. Park, K. Development of Enhancing Life Span Technology FRP Waterfront Structures Using FRP Hybrid Bars; Report No. KICT-2014-162; Korea Institute of Civil Engineering and Building Technology (KICT): Gyeonggi-Do, Korea, 2014. (In Korean)

18. Kocaoz, S.; Samaranayake, V.A.; Nanni, A. Tensile characterization of glass FRP bars. Compos. Part B 2005, 36, 127-134. [CrossRef]

19. Kim, K. Design and Construction Technology for Concrete Structures Using Advanced Composite Materials; Report No. KICT-2008-165; Korea Institute of Civil Engineering and Building Technology (KICT): Gyeonggi-Do, Korea, 2008; p. 214. (In Korean)

(C) 2017 by the authors. Licensee MDPI, Basel, Switzerland. This article is an open access article distributed under the terms and conditions of the Creative Commons Attribution (CC BY) license (http://creativecommons.org/licenses/by/4.0/). 